\title{
ANALISIS PENGARUH KUALITAS LAYANAN TERHADAP KEPUASAN WISATAWAN PADA AGROWISATA SAPI PERAH DI BERASTAGI
}

\author{
Dian Retno Intan*, Wildani Lubis ${ }^{1}$, Wahyuni Umami Harahap ${ }^{1}$ \\ ${ }^{1}$ Department of Agribusiness, Faculty of Agriculture, University of Muhammadiyah \\ Sumatera Utara \\ E-mail: dianretno@umsu.ac.id
}

\begin{abstract}
ABSTRAK
Analisis Pengaruh Kualitas Layanan Terhadap Kepuasan Wisatawan Pada Agrowisata Sapi Perah Di Berastagi.

Agrowisata merupakan usaha diversifikasi dan peningkatan kualitas dari usaha tani, dimana pada usaha ini menekankan pada penjualan jasa kepada konsumen. Hal ini berarti dalam praktiknya pemilik akan memberikan fokus lebih banyak pada penyediaan layanan. Dalam memasarkan jasa khususnya, kualitas layanan merupakan hal yang sangat penting, baik yang terlihat (tangible) maupun yang tidak (intangible). Agrowisata yang menjadi objek penelitian merupakan satu-satunya peternakan sapi perah di Sumatera Utara. Banyaknya pengalaman dan hal-hal lain yang ditawarkan oleh perusahaan ini membuat perusahaan dan pengelola harus secara ekstra menampilkan dan menyediakan layanan dengan kualitas yang baik. Oleh karena itu, perusahaan ini harus membuat strategi yang fokus pada kepuasaan konsumen, mempertahankan, dan menciptakan loyalitas konsumen melalui layanan yang diberikan. Populasi penelitian ini adalah wisatawan atau pengunjung Agrowisata Sapi Perah yang bertempat di Berastagi. Sampel ditentukan dengan menggunakan non probability sampling dengan teknik accidental dan didapat sampel sebanyak 75 orang wisatawan. Data dikumpulkan dengan menggunakan kuesioner atau angket yang diberikan kepada pengunjung/ wisatawan yang berkunjung pada saat penelitian dilakukan (accidental sampling). Data yang didapat akan dianalisis menggunakan SEM (structural equation model) dengan menggunakan software PLS (partial least square). Hasil penelitian ini menunjukkan bahwa konstruk kualitas layanan memiliki pengaruh positif dan signifikan terhadap kepuasan wisatawan agrowisata sapi perah terutama pada variable empati. Penelitian ini diharapkan mampu membantu pihak agrowisata meningkatkan kualitas layanan yang akan menciptakan kepuasan pengunjung.
\end{abstract}

Kata Kunci: Agrowisata, kualitas layanan agrowisata, sapi perah

\begin{abstract}
Analysis Of The Effect Of Service Quality On Tourist Satisfaction on Dairy Cow Agrotourism in Berastagi.

Agrotourism is one way to diversify and improve the quality of farming, which in this business emphasizes the sale of services to consumers. It means that in practice the owner will focus more on service delivery. In marketing services in particular, service quality is very important, both tangible and intangible. Agrotourism which is the object of research is the only dairy farm in North Sumatra. The amount of experience and other things offered by this company makes the company and manager have to extravagantly display and provide services with good quality. Therefore, this company must create a strategy that focuses on customer satisfaction, maintaining, and creating customer loyalty through the services provided. The population of this study are tourists or visitors to the Dairy Cow Agrotourism located in Berastagi. The sample was determined using non-probability sampling with accidental technique and obtained a sample of 75 tourists. Data is collected using questionnaires that given to visitors/tourists who visited at the time the research was conducted (accidental sampling). The data obtained will be analyzed using SEM (structural equation model) using PLS (partial least square) software. The results of this study indicate that the service quality construct has a positive and significant influence on the satisfaction of dairy agrotourism tourists, especially on the empathy variable. This research is expected to be able to help the agro-tourism to improve the quality of services that will create visitor satisfaction.
\end{abstract}

Keywords: Agrotourism, quality of agrotourism services, dairy 


\section{PENDAHULUAN}

Peranan sektor pariwisata nasional semakin penting sejalan dengan perkembangan dan kontribusi yang diberikan sektor pariwisata melalui penerimaan devisa, pendapatan daerah, pengembangan wilayah, maupun penyerapan investasi dan tenaga kerja di seluruh wilayah Indonesia. Berdasarkan data BPS, kontribusi periwisata terhadap PDB 5 tahun terakhir adalah sebesar $4 \%$. Nilai ini mungkin kecil, namun sektor pariwisata memiliki multiplier effect atau sektor pengali. Maksudnya adalah adanya mekanisme tarikan dan dorongan terhadap sector ekonomi lain yang terkait dengan sector pariwisata, seperti hotel dan restoran, angkutan, industry kerajinan dan lainnya. Efek ini mampu membantu sector lain untuk tumbuh dan berkembang lebih cepat dan pada akhirnya mampu meningkatkan eknonomi daerah dan menciptakan lapangan pekerjaan.

Dalam bidang pertanian, usaha pariwisata disebut dengan agrowisata, Agrowisata atau wisata pertanian adalah rangkaian aktivitas perjalanan wisata yang memanfaatkan lokasi atau sector pertanian mulai dari awal produksi hingga diperoleh produk pertanian dalam berbagai sistem dan skala dengan tujuan memperluas pengetahuan, pemahaman, pengalaman, dan rekreasi di bidang pertanian. Salah satu agrowisata yang terkenal di Berastagi adalah agrowisata sapi perah. Agrowisata ini merupakan pariwisata terpadu peternakan-pertanianrestoran di Berastagi. Agrowisata dengan konsep farm to table ini menyajikan menu khas daerah dan menu internasional dengan bahan baku dari peternakan dan pertanian yang langsung disajikan segar di restoran. Agrowisata ini tidak hanya menawarkan makanan dan pemandangan yang bagus saja, namun juga dapat menjadi sarana edukasi. Pengunjung dapat melihat proses produksi turunan susu, area proses ice cream, area proses keju, dan lainnya dari balik kaca (agar tidak terjadi kontaminasi). Selain itu, pengunjung juga dapat merasakan pengalaman memeras susu sapi secara langsung.

Dalam memasarkan jasa khususnya, kualitas layanan merupakan hal yang sangat penting, baik yang terlihat (tangible) maupun yang tidak (intangible). Hal ini disebabkan ketatnya persaingan antar usaha dibidang ini yang menyebabkan pengelola harus mampu melihat dan memanfaatkan sumber daya dan kesempatan yang ada. Wisatawan yang berkunjung ke agrowisata tentu saja membawa harapan atau ekspektasi dalam benaknya. Perusahaan harus mampu menawarkan layanan yang mampu setidaknya memenuhi harapan konsumen. Apabila kualitas layanan yang diterima konsumen melebihi harapannya, maka konsumen akan merasa puas, Sebaliknya, jika kualitas layanan yang diberikan perusahaan tidak mampu memenuhi ekspektasi konsumen, maka konsumen akan merasa kecewa. Kepuasan konsumen adalah tingkat perasaan seseorang setelah membandingkan kinerja produk atau jasa yang ia rasakan dengan harapannya. Tingkat kepuasan merupakan fungsi dari perbedaan antara kinerja yang dirasakan (perceived performance) dengan kinerja yang diharapkan (expectated performance) (Santoso, 2006). Oleh karena itu, evaluasi maupun perbaikan kualitas produk/jasa menjadi sangat penting dilakukan jika perusahaan ingin tetap eksis dimata pelanggannya.

\section{METODE PENELITIAN}

Penelitian ini merupakan penelitian deskriptif kuantitatif, dimana tujuan penelitian ini adlah untuk mendeskripsikan fenomena dalam bentuk angka-angka yang memiliki makna. Data 
dikumpulkan dalam bentuk skala likert dan diolah dengan menggunakan analisis SEM (Structural Equation Model). Analisis ini dipilih untuk menguji berbagai hubungan secara komprehensif ((Bollen and Long, (1993) dalam Carlson dan O'Cass (2010)).

Penelitian ini memiliki lima variable independent yang mewakili kualitas layanan dan akan dianalisis hubungannya dengan kepuasan wisatawan. Konstruk kualitas layanan dirincikan dalam lima variable berikut (Parasuraman, 2001).

1. Bukti fisik (Tangibles) yaitu kemampuan perusahaan dalam menunjukkan sarana, prasarana, daya tarik, dan semua yang telah diklaim dimiliki perusahaan sesuai dengan apa yang dijanjikan. Variabel ini terdiri dari 9 indikator reflektif.

2. Kehandalan (Reliability) yaitu suatu kemampuan melakukan pelayanan sesuai dengan apa yang telah dijanjikan. Variabel ini terdiri dari 4 indikator reflektif.

3. Ketanggapan (Responsiveness) yaitu suatu kemampuan dalam memberikan bantuan kepada pelanggan dengan cepat dan tepat. Variabel ini terdiri dari 5 indikator reflektif

4. Jaminan (Assurance) yaitu kepastian yang akan didapatkan oleh pelanggan apabila menggunakan jasa perusahaan antara lain berhubungan dengan komunikasi, kredibilitas, keamanan, dan kompetensi. Variabel ini terdiri dari 5 indikator reflektif.

5. Simpati (Empathy) yaitu kemampuan dalam memberikan pelayanan yang tulus dan bersifat pribadi kepada para pelanggan dengan berupaya memahami keinginan yang dibutuhkan pelanggan. Variabel ini terdiri dari 6 indikator reflektif.

Penelitian ini memiliki populasi responden berupa wisatawan Agrowisata Sapi Perah dan sedang berkunjung ke tempat tersebut saat penelitian dilakukan. Sampel penelitian ditentukan menggunakan non probability sampling dengan accidental sampling dan convenience sampling dan ditemukan 75 responden. Data yang digunakan dalam penelitian ini adalah data primer dan data sekunder. Data primer didapat dengan melakukan observasi dan penggunaan kuesioner (angket), sedangkan data sekunder dikumpulkan melalui studi Pustaka dan penelitian terdahulu.

Analisis data yang digunakan dalam penelitian ini adalah dengan menggunakan SEM-PLS dengan menggunakan software WarpPLS 7.0. Model konseptual dalam penelitian dapat dilihat pada gambar 1 . 


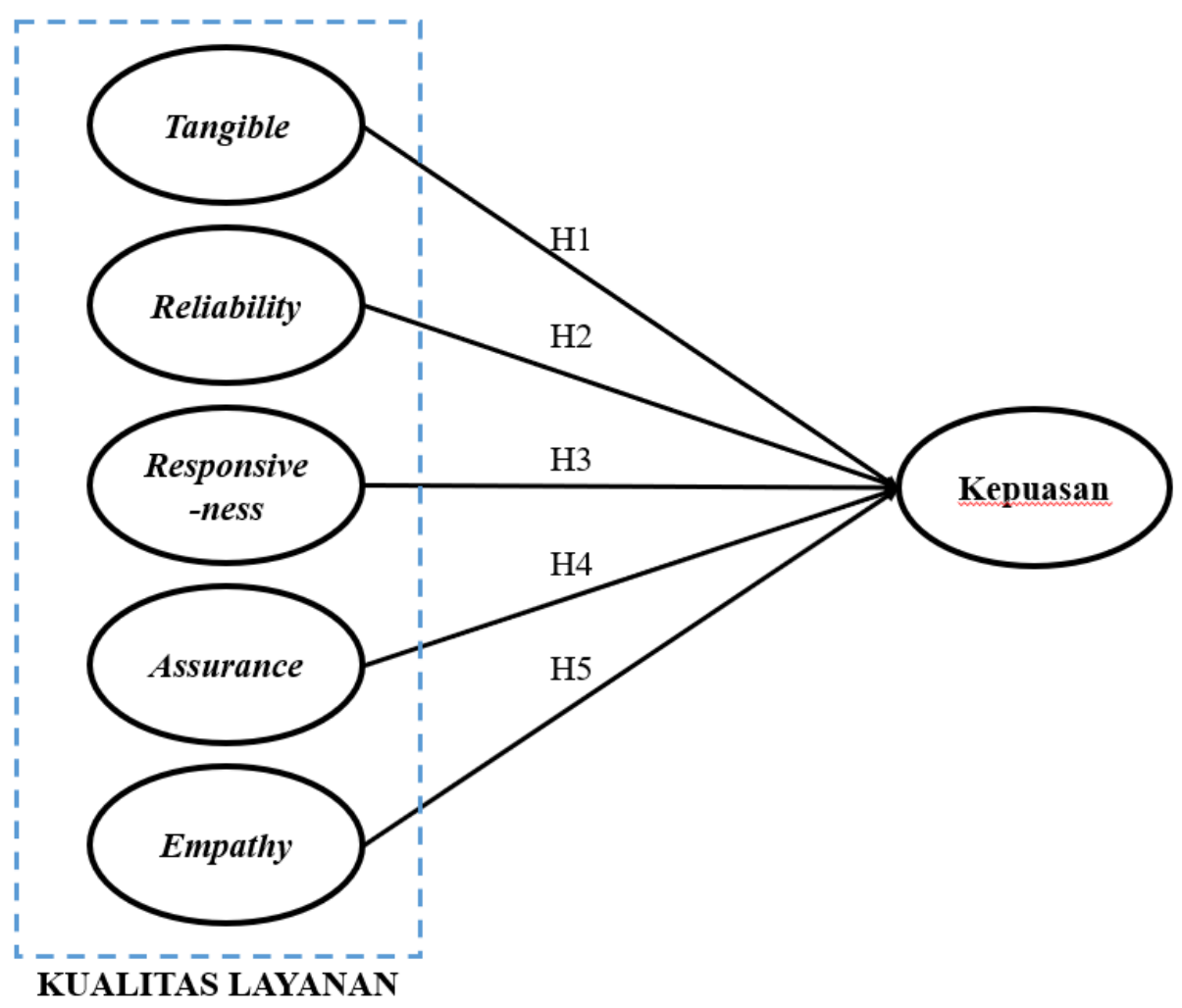

Gambar 1. Model Konseptual

Adapun hipotesis dalam penelitian ini adalah sebagai berikut.

$\begin{array}{lll}\mathrm{H} 1 & : & \text { Layanan tangible berpengaruh positif terhadap kepuasan wisatawan. } \\ \mathrm{H} 2 & : & \text { Layanan yang handal berpengaruh positif terhadap kepuasan wisatawan. } \\ \mathrm{H} 3 & : & \text { Layanan yang tanggap berpengaruh positif terhadap kepuasan wisatawan. } \\ \mathrm{H} 4 & : & \text { Jaminan layanan berpengaruh positif terhadap kepuasan wisatawan. } \\ \mathrm{H} 5 & : & \text { Layanan yang penuh dengan empati berpengaruh positif terhadap kepuasan }\end{array}$
wisatawan.

\section{HASIL DAN PEMBAHASAN}

Sebelum melakukan pengujian hipotesis, dilakukan terlebih dahulu pengujian terhadap alat ukur yang digunakan dalam penelitian, yaitu indicator. Indikator-indikator yang digunakan untuk mengukur variabel laten terlebih dahulu diuji validitas dan reliabilitasnya, sehingga hasil penelitian nantinya dapat dipergunakan di masa depan.

\section{Uji Validitas}

Uji validitas merupakan uji yang memperlihatkan sejauh mana indikator yang kita gunakan mampu mengukur variabel. Indikator yang valid dalam mengukur sebuah variable merupakan indicator yang saling berkorelasi. Penelitian ini menggunakan analisis convergent validity dengan menggunakan nilai Average Variance Extracted (AVE). Kriterianya adalah apabila nilai AVE lebih besar dari 0.5, maka instrument tersebut dinyatakan valid. Hasil pengujian convergent validity menggunakan AVE disajikan dalam tabel berikut: 
Tabel 1. Hasil Convergent Validity

\begin{tabular}{|c|c|}
\hline Variabel Laten & Nilai AVE \\
\hline Tangible & 0,582 \\
\hline Reliability & 0,731 \\
\hline Responsiveness & 0,624 \\
\hline Assurance & 0,632 \\
\hline Emphaty & 0,642 \\
\hline Kepuasan & 0,643 \\
\hline
\end{tabular}

Sumber : data WarpPLS, 2021 (diolah)

Berdasarkan hasil convergent validity, diketahui bahwa nilai AVE semua variabel dalam penelitian lebih besar dari 0.5 sehingga dapat disimpulkan bahwa indicator yang digunakan dalam penelitian untuk mengukur variabel laten adalah valid.

\section{Uji Reliabilitas}

Uji reliabilitas (uji keandalan) merupakan pengujian yang dilakukan untuk melihat konsistensi indicator pengukuran untuk mengukur variabel secara berulang dari waktu ke waktu. Penelitian ini menggunakan koefisien composite reliability sebagai alat ukur konsistensi indicator dengan kriteria reliabel jika nilai koefisien > 0,7 (Ghozali, 2016). Adapun output dari uji composite reliability ditunjukkan pada tabel 2 .

Tabel 2. Hasil Composite Reliability

\begin{tabular}{cc}
\hline Variabel & Composite Reliability \\
\hline Tangible & 0.798 \\
Reliability & 0.739 \\
Responsiveness & 0.845 \\
Assurance & 0.865 \\
Emphaty & 0.836 \\
Kepuasan Wisatawan & 0.878 \\
\hline
\end{tabular}

Sumber : data WarpPLS, 2021 (diolah)

Berdasarkan hasil uji reliabilitas dengan menggunakan WarpPLS 7.0, dari composite reliability bernilai lebih besar dari 0.7. Artinya, semua indicator yang mengukur variable tangible, reliability, responsiveness, assurance, emphaty, dan kepuasan dinyatakan reliabel.

\section{Pengujian Hipotesis}

Pengujian hipotesis dilakukan dengan melihat koefisien jalur dari output analisis SEM. Koefisien ini menunjukkan arah dan besarnya hubungan variabel eksogen dengan variabel endogen. Namun sebelum melihat pengaruh variabel eksogen terhadap variabel endogen, terlebih dahulu dievaluasi model structural yang digunakan dalam penelitian dengan melihat koefisien determinasinya $\left(\mathrm{R}^{2}\right)$. Besar nilai koefisien 
ini akan menunjukkan seberapa besar variable bebas mampu menjelaskan variable terikatnya.

Pada peneitian ini menggunakan satu variable terikat atau variable endogen yaitu kepuasan wisatawan. Bersasarkan hasil goodness of fit diketahui bahwa nilai $\mathrm{R}^{2}$ variabel kepuasan wisatawan adalah sebesar 0,521. Hal ini menunjukkan bahwa keragaman variable kepuasan wisatawan mampu dijelaskan oleh variable-variabel kualitas layanan sebesar 52,1\%. Dengan kata lain, kelima variable kualitas layanan, yaitu tangible, reliability, responsiveness, assurance, dan emphaty berkontribusi sebesar 52,1\% dalam kepuasan wisatawan sedangkan $47,9 \%$ sisanya merupakan kontribusi variable lain di luar variable penelitian ini.

Hasil analisis koefisien jalur disajikan pada gambar 2 di bawah ini.

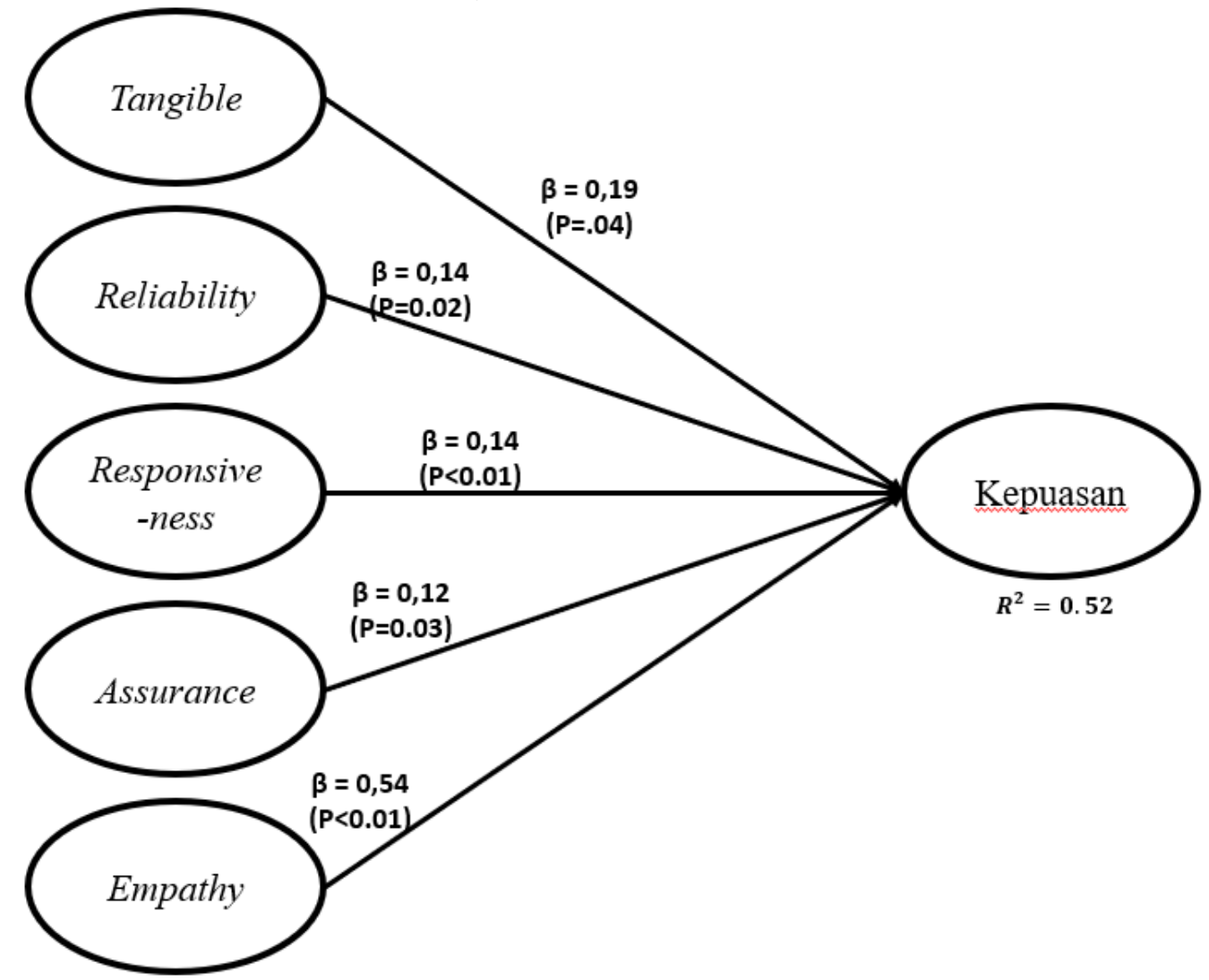

Gambar 2. Analisis Koefisien Jalur

Berdasarkan analisis jalur yang ditunjukkan pada gambar 2, diketahui bahwa kelima variabel kualitas layanan memiliki pengaruh yang positif dan signifikan terhadap kepuasan wisatawan. Variabel yang memiliki pengaruh paling besar adalah emphaty. Variabel empati memiliki nilai pengaruh sebesar 0,52 dengan $\mathrm{P}$ value sebesar $<0.01$.
Empati merupakan perhatian perusahaan yang diberikan kepada konsumen, dalam hal ini adalah wisatawan. Perhatian yang diberikan perusahaan dapat berupa fasilitas yang nyaman, letak fasilitas yang strategis, kebersihan pemandu wisata yang kompeten, dan lainnya. Hal ini sejalan dengan hasil penelitian Gupta dkk. (1995) yang menemukan empati sebagai variabel penting layanan, menyiratkan bahwa 
pengertian dan perhatian individual mempengaruhi kepuasan pelanggan. Selain itu, sikap, pengetahuan, dan keterampilan pemandu wisata juga mempengaruhi kepuasan pengunjung (Lin et al., 2018). Engeset \& Heggem, (2015) juga menambahkan bahwa kontak pribadi dengan konsumen merupakan kunci penting dalam menjaga keberadaan perusahaan.

Dalam agrowisata, empati juga mencerminkan cara staff perusahaan atau pemandu wisata berinteraksi dengan wisatawan. Pentingnya hal ini juga ditunjukkan dengan hasil penelitian Karimah dkk. (2021) yang menjelaskan bahwa staf perusahaan yang memberikan perhatian penuh kepada pengunjung membuat perusahaan mendapatkan kepuasan dari pengunjung. Staf perusahaan yang menyambut pengunjung dengan senyum dan salam akan lebih berkesan dan memberikan penilaian positif sebelum memulai kegiatan. Pemahaman yang efektif, hubungan komunikasi yang baik akan membuat pelanggan merasa dihargai. Dengan demikian, ini akan mengarah pada harapan positif pelanggan terhadap kualitas layanan yang telah dilaksanakan oleh perusahaan.

Variabel yang paling berpengaruh kedua adalah layanan yang tangible. Layanan tangible atau kualitas fisik merupakan sesuatu yang ditampilkan perusahaan yang berwujud dan dapat dilihat, seperti penampilan fasilitas fisik, peralatan, dan penampilan personel atau staf perusahaan. Kualitas fisik memiliki nilai koefisien jalur sebesar 0,19 dengan $\mathrm{P}$ value sebesar 0.02 yang berarti bahwa kualitas fisik memberikan pengaruh yang positif dan signifikan terhadap kepuasan wisatawan. Hasil ini sejalan dengan penemuan Wakefield dan Blodgett (1999) bahwa "fisik nyata" lingkungan memainkan peran penting dalam menghasilkan kegembiraan yang memainkan peran penting dalam menentukan niat dan keinginan pelanggan untuk merekomendasikan.

Indrayanti et al. (2019) menyatakan bahwa atribut pelayanan yang dapat meningkatkan kepuasan pengunjung adalah variasi atraksi wisata, infrastruktur, dan fasilitas yang memadai termasuk kebersihan toilet. Tersedianya fasilitas pendukung seperti kamar kecil yang bersih dan memadai serta sarana ibadah, penampilan staf dan penataan fasilitas yang rapi dan adanya pemandangan alam yang indah dan berbeda dengan tempat wisata lainnya juga meningkatkan kepuasan wisatawan dalam sebuah agrowisata (Lestari et al., 2016).

Variabel selanjutnya adalah variabel yang memiliki pengaruh yang sama besar terhadap kepuasan wisatawan, yaitu variabel reliability dan responsiveness. Kedua variabel ini memiliki koefisien jalur yang sama, yaitu 0,14 dengan nilai $\mathrm{P}$ value dibawah 0.05 . Hal ini berarti kedua variabel memiliki pengaruh positif dan signifikan terhadap kepuasan wisatawan. Variabel reliability merupakan kemampuan untuk melakukan layanan yang dijanjikan dengan andal dan akurat. Agrowisata harus konsisten terhadap apa yang telah mereka katakan, janjikan dan tawarkan kepada pengunjung ataupun calon pengunjung. Agrowisata sapi perah menawarkan pengalaman untuk melihat secara langsung proses pembuatan produk olahan susu, maka agrowisata membuat fasilitas seperti lorong yang memiliki dinding kaca yang terhubung dengan kegiatan produksi hasil olahan susu sapi. Wisatawan dapat melihat langsung proses pengolahan berbagai produk dengan bahan dasar susu segar dan juga dapat mencicipi hasil olahan tersebut, baik dalam bentuk susu segar dengan berbagai varian rasa, es krim, keju, dan sebagainya. Gronroos (2001) telah 
menyarankan bahwa keandalan penting bagi pelanggan sehingga mereka dapat mengandalkan penyedia layanan, karyawannya, dan sistem yang dibuat oleh penyedia layanan.

Variabel responsiveness merupakan kemauan untuk membantu dan menyediakan layanan dengan cepat. Ketika sebuah perusahaan (dalam hal ini bisa diwakilkan dengan pemandu wisata) responsif terhadap wisatawa, wisatawan akan merasa bahwa kebutuhan dan keinginannya terpenuhi. Dengan demikian, itu akan mengarah pada peningkatan ataupun terciptanya kepuasan atas kualitas layanan yang mereka terima. Sebaliknya, Gandhy et al. (2019) menjelaskan apabila konsumen dibiarkan menunggu staf datang karena mereka meninggalkan tempat karena beberapa alasan, dan staf yang kurang professional menjawab pertanyaan pelanggan akan membuat pengunjung bingung dan menurunkan nilai kepuasan atas layanan. Selain itu, responsiveness juga berkaitan dengan penanganan keluhan pengunjung. Keluhan dari pengunjung membuat perusahaan harus memperhatikan sikap karyawan dalam bertransaksi dengan keluhan, kesiapan dalam membantu pengunjung dalam situasi mendadak, kecepatan layanan untuk mengurangi waktu tunggu pengunjung, kesediaan untuk membantu pengunjung langsung, dan ketangkasan petugas lapangan dalam membantu pengunjung (Lestari et al., 2016). Jika terjadi sebuah kegagalan dalam penyampaian layanan, namun perusahaan mampu untuk melakukan pemulihan (recovery) dengan cepat dan professional, hal ini dapat menciptakan persepsi kualitas dan kepuasan yang sangat positif. Seperti yang pendapat Carmen (2000) bahwa metode utama penanganan keluhan dan retensi pelanggan adalah dengan cara cepat tanggap.
Variabel dengan pengaruh paling kecil diantara lima variabel kualitas layanan adalah jaminan (assurance). Variabel ini ditunjukkan dengan pengetahuan dan kesopanan karyawan serta kemampuan mereka untuk membuat wisatawan percaya.

Pelanggan merasakan risiko tinggi ketika mereka merasa tidak yakin tentang hasilnya. Kepercayaan dan keyakinan karyawan mewujudkan organisasi tempat mereka bekerja. Pada tahap awal hubungan, pelanggan dapat menggunakan bukti nyata untuk menilai dimensi jaminan. Bukti yang terlihat seperti gelar, penghargaan atau sertifikasi khusus dapat memberikan kepercayaan kepada pelanggan baru. Wisatawan akan merasa aman dan percaya jika pemandu wisata mampu menguasai semua informasi mengenai layanan yang disajikan dan berbagai fasilitas yang ditawarkan serta mampu memberikan informasi yang akurat kepada wisatawan. Agrowisata sapi perah juga menyediakan pengalaman langsung dalam memerah susu sapi. Kegiatan ini haruslah dipandu dan didampingi oleh staf yang professional, sehingga tidak terjadi kesalahan yang dapat menciptakan pengalaman buruk bagi pengunjung dan juga sapi yang diperah. Informasi dan pendampingan langsung dari pemandu atau staf kompeten di bidangnya terkait hal ini membuat pengunjung merasa aman dan percaya diri dengan pelayanan yang diberikan dan sangat direkomendasikan. Alanazi (2016) menyatakan bahwa keselamatan akan meningkatkan kepuasan pelanggan.

\section{KESIMPULAN}

Kualitas layanan agrowisata yang terdiri dari lima variabel yaitu tangible, reliability, responsiveness, assurance, dan emphaty secara keseluruhan memiliki pengaruh positif dan signifikan terhadap 
kepuasan wisatawan. Artinya, semakin baik kualitas layanan yang diberikan, maka semakin meningkat pula kepuasan yang didapat oleh wisatawan. Variabel yang memiliki pengaruh paling besar berdasarkan persepsi wisatawan adalah emphaty yang menitikberatkan pada hubungan antara perusahaan dan wisatawan.

\section{DAFTAR PUSTAKA}

Alanazi, A. (2016). Factors that Affect and Enhance Customer Satisfaction. Journal of Research in Business and Management, 4(9), 80 -88 .

Carlson J. dan O'Cass A. (2010). Exploring The Relationships Between E-Service Quality, Satisfaction, Attitudes and Behaviours in Content-Driven EService Web Sites. Journal of Services Marketing, 24(2), 112 127.

Carmen, J.M. (2000). Patient Perceptions of Service Quality: Combining the Dimensions. Journal of Service Marketing, 14(4), 337 -352.

Engeset, A. B., dan R. Heggem. (2015). Strategies in Norwegian Farm Tourism: Product Development, Challenges, and Solutions. Scandinavian Journal of Hospitality and Tourism, 15(1), 122 $-137$.

Gandhy, A., M. Chang, dan S. Rahmi. (2019). Service Quality and Customer Satisfaction in Thermal Tourism. Junal Organisasi dan Manajemen, 15(2), 153 - 165.

Ghozali, I. (2016). Aplikasi Analisis Multivariete Dengan Program (IBM. SPSS). Edisi 8. Semarang:
Badan Penerbit Universitas Diponegoro.

Gronroos, C. (2001). The Perceived Service Quality Concept - A Mistake?", Managing Service Quality: An International Journal, 11(3), $150-152$.

Gupta, A. dan I. Chen. (1995). Service Quality: Implications for Management Development. International Journal of Quality Management, 12(7), 28 - 35.

Indrayanti, T., Jamhari, Mulyo, J. H., \& Masyhuri. (2019). The Analysis of Community Based Agrotourism Customer Satisfaction in Yogyakarta. Journal of Environmental Management and Tourism, 10(8), 1796 - 1806.

Karimah, M., A. Setiadi, dan Mukson. (2021). Analysis of Visitors's Satisfaction on the Quality of Omah Salak Agro-Tourism Services. SOCA: Jurnal Sosial Ekonomi Pertanian, 15(1), 85 - 99.

Lestari, B., D. Manumono, dan A. Ambarsari. (2016). Analisis Pengaruh Kualitas Pelayanan terhadap Kepuasan Konsumen Agrowisata (Studi kasus di Wisata Agro Tambi PT Perkebunan Tambi Wonosobo. Jurnal MASEPI, 1(1), 1 -17 .

Lin, Y. C., M. L. Lin, dan Y. C. Chen. (2018). Examining the Impact of Tour Guides' Professional Competences on Service Quality, Tourist Satisfaction and Repurchase Intentions towards Package Tour Products. Journal of Tourism and Hospitality Management, 6(2), 02 - 114.

Parasuraman, A dan V.A. Zeithaml 2001. Delivering Quality Service. 
Diterjemahkan oleh Sutanto. New York: The Free Press.

Santoso, H. (2006). Meningkatkan Kualitas Layanan Industri Jasa melalui Pendekatan Integrasi Metoda SERVQUAL-Six Sigma atau

SERVQUAL-QFD. Jurnal J@ti Undip, 1(1), 85 - 106.
Wakefield, K.L. dan J. G. Blodgett. (1999). Customer Response to Intangible and Tangible Service Factors. Journal of Psychology \& Marketing, 16(1), 51-68. 